\title{
O Uso das TIC's e o Cyberbullying: Um Estudo Realizado com Escolares do Município de Paranaguá/PR
}

\author{
Sabrina Pedersen Galani ${ }^{1}$, Alisson Eduardo Ferreira Machado ${ }^{1}$, Clóvis \\ Wanzinack ${ }^{1}$ \\ ${ }^{1}$ Universidade Federal do Paraná (UFPR) \\ Rua Jaguariaíva, n 512, Caiobá, Matinhos, Paraná/PR \\ (bina_bella0@hotmail.com; alisson@ufpr.br; clovis_cwb@yahoo.com)
}

\begin{abstract}
The present study aimed to determine the prevalence of the use of Information and Communication Technologies (ICTs) and instances of cyberbullying among students, from 5th to 9th grade, the municipality of Paranaguá/PR. We used Survey methodology and the sample consisted of 252 participants. The results show that students make use of ICT and there incidence of cyberbullying. This scenario allows reflections and subsidize actions that enable interventions to minimize the problem by tackling truancy and improving the quality of education.
\end{abstract}

Resumo. O presente estudo teve por objetivo verificar a prevalência do uso das Tecnologias de Informação e Comunicação (TIC's) e das ocorrências de cyberbullying entre escolares, da $5^{a}$ a $9^{a}$ série, do município de Paranaguá/PR. Utilizou-se metodologia de Survey e a amostra foi constituída por 252 participantes. Os resultados revelam que os estudantes fazem uso das TIC's e há incidência de cyberbullying. Esse panorama permite reflexões e subsidiam ações que viabilizem intervenções para a minimização do problema, combatendo a evasão escolar e melhorando a qualidade da educação.

\section{Introdução}

O litoral do Paraná, distante $120 \mathrm{~km}$ da capital Curitiba, registra um dos menores Índices de Desenvolvimento Humano (IDH) do estado. A região abrange 7 municípios (Antonina, Guaraqueçaba, Guaratuba, Matinhos, Morretes, Paranaguá e Pontal do Paraná) que apresentam características demográficas, ambientais, econômicas e de saúde diversas, embora com algumas peculiaridades em comum.

Paranaguá, município do estudo, é uma cidade portuária com aproximadamente $150 \mathrm{mil}$ habitantes e que possui população distribuída predominantemente entre jovens, aproximadamente 27 mil entre 10 e 19 anos. Apesar de gerar desenvolvimento econômico, advindo principalmente das atividades portuárias, esse se distribui de forma muito desigual entre a população, contando com uma expressiva parcela da população com indicadores econômicos discrepantes da capital do estado (IPARDES, 2012; IBGE, 2010). 
Sem querer entrar em determinismos e sem querer assimilar a pobreza com violência, percebe-se que em conjunturas como estas, assinaladas por circunstâncias de amplas iniquidades sociais e lacunas do aparato Estatal, vêm à tona problemas como (re)produção de diversos tipos de preconceitos e violências, que podem iniciar ou se intensificar no ambiente escolar tanto presencial quanto virtual.

A região se dispõe do Setor Litoral da Universidade Federal do Paraná (UFPR), única Instituição de Ensino Superior (IES) Federal, implantado em 2005 no contexto do Programa de Reestruturação e Expansão das Universidades Federais (REUNI) e integra o Plano de Desenvolvimento Institucional (PDI) da Universidade, representando um movimento de expansão visando o desenvolvimento regional da região do litoral, através de parcerias com a comunidade e órgãos locais, pautados na responsabilidade social e construção de práticas pedagógicas inovadoras (UFPR, 2008).

O Curso de Bacharelado em Informática e Cidadania, criado em 2009, no Setor Litoral da UFPR tem por objetivo conhecer e compreender os contextos e necessidades sociais e propor alternativas de cooperação tecnológico-científico e interdisciplinar para agir na melhoria da qualidade de vida da sociedade (UFPR, 2009). Dentro deste contexto, o Projeto "Cyberbullying: Violência por meio das TIC's na Educação" foi desenvolvido em parceria com escolas do ensino fundamental da rede pública do município de Paranaguá/PR, com objetivo de conhecer e compreender as questões envolvidas entre o uso das TIC's e a violência no contexto escolar.

Para Oliveira, Ferreira e Costa (2011), os problemas relacionados à violência no contexto escolar se fazem presentes, pois o modo de vida do século XXI trouxe à tona elementos que, antes, não eram tão percebidos ou tão evidenciados como na atualidade no que se refere ao cotidiano escolar, tais como: agressão entre docentes e discentes, violência dentro e fora da escola, desigualdades sociais, pressões sociais, entre outros.

O bullying no contexto escolar é um comportamento agressivo, persistente e intencional, caracterizado pela repetitividade e assimetria de forças, com a intenção de causar dano físico ou moral através da violência em um ou mais estudantes que são mais fracos e incapazes de se defender (Bandeira e Hutz, 2010; Calbo et al., 2009; Gomes e Rezende, 2011; Wanzinack, 2014).

No contexto virtual esse fenômeno é denominado cyberbullying, onde são utilizadas as TIC's para dar apoio a comportamentos deliberados, repetitivos e hostis praticados por um indivíduo ou grupo com a intenção de prejudicar o outro (Wanzinack, 2014).

Essas agressões hoje pulam os muros de colégios, tornando até lugares tradicionalmente considerados mais seguros, como os lares, em locais vulneráveis. Isso porque os ataques de cyberbullying podem acontecer em momentos inesperados, como nas madrugadas, quando a vítima está dormindo em seu quarto, com a sensação de um lugar seguro. Segundo Casagrande et al. (2011), essas situações de violências podem produzir traumas que interferem na construção das identidades de muitos jovens.

Diante o exposto, o presente trabalho tem como objetivo geral verificar a prevalência do uso das TIC's e ocorrências do cyberbullying por escolares de ensino fundamental, da $5^{\circ}$ a $9^{\circ}$ série, do município de Paranaguá/PR. 


\section{Métodos}

Esta pesquisa é caracterizada como exploratória, pois é a mais adequada para situações em que se pretende ter maior familiaridade e compreensão aprofundada de um fenômeno. Utilizou-se o método Survey com desenho interseccional, que limita a adoção de análises descritivas e impede qualquer tentativa de generalização dos resultados e trabalhou-se com amostra não probabilística (ou acidental).

Para tanto foi elaborado um questionário. O pré-teste foi realizado com estudantes do Curso de Bacharelado de Informática e Cidadania da UFPR. Depois de testado e aperfeiçoado, o instrumento foi dividido em 3 partes, sendo elas: 1. Caracterização Individual; 2. Caracterização das TIC's utilizadas pelos estudantes; e, 3. Caracterização dos tipos de agressão, totalizando 30 questões.

A aplicação ocorreu entre novembro e dezembro de 2013, direcionada para estudantes de 1 escola do ensino fundamental, com estudantes da $5^{\circ}$ a $9^{\circ}$ série, do município de Paranaguá/PR. A escolha da escola se deu por ser a maior escola do município. Os pesquisadores realizaram a aplicação in loco, nas salas de aula, e foi realizado da seguinte forma: 1. Explicação da Pesquisa; 2. Explicação quanto ao autopreenchimento do questionário; 3 . Preenchimento do questionário pelo aluno; 4. Entrega do questionário para os pesquisadores.

Foram devolvidos 252 questionários considerados válidos. Para a análise e estatística dos dados utilizou-se uma base de dados online, através da intranet para os pesquisadores, disponível no site do Projeto (http://www.bullyinglitoraldoparana.org/). Isso facilitou a tabulação e os acessos aos dados.

\section{Resultados e Discussão}

Para Lopes (2004) houve uma época na qual eram necessárias explicações na utilização da informática na educação, mas nos dias atuais há um consenso, afinal vivemos em um mundo tecnológico, onde novos meios de comunicação e interatividade tecnológica veem tendo mais usabilidades dentro de instituições de ensino como forma de apoio ao processo de ensino aprendizagem.

A presente pesquisa teve amostra constituída por 252 estudantes, sendo 130 do sexo masculino e 122 do sexo feminino, com idade variando de 13 a 18 anos, sendo que a maioria ( $>60 \%$ ) se encontra na faixa de 11 a 14 anos. Aproximadamente metade, $52,1 \%$ dos alunos utilizam o celular; $20,8 \%$ usam computadores portáteis; $6,8 \%$ utilizam tablet; e, $23 \%$ tem acesso ao computador. 

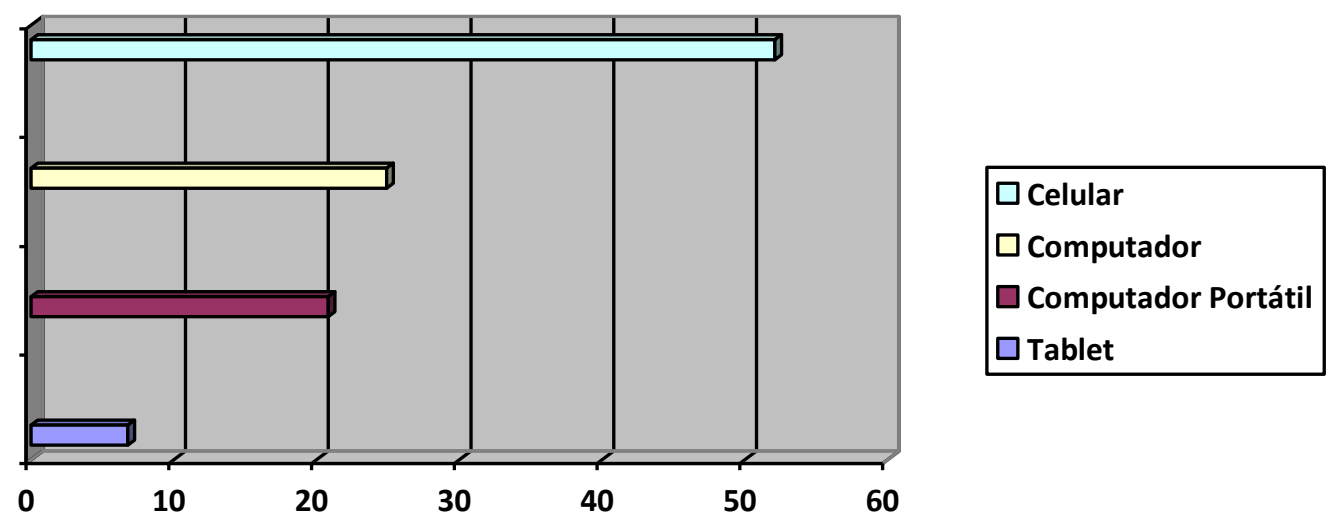

\section{Gráfico 1. Utilização das TIC's por estudantes de do município de Paranaguá/PR. Divididos pelas variáveis: Celular, Computador, Computador Portátil e Tablet. Fonte: O Autor, 2014.}

Em 2004, um Inquérito à população promovido pelo gabinete do Conselho de Ministros (OIC, 2004), revelava que 54\% da população utilizava, já naquela data, o computador, que a taxa média de crescimento anual de utilizadores da Internet era de $21 \%$, que $92 \%$ dos utilizadores tinham entre os 15 e os 19 anos e eram estudantes $(98 \%)$ a frequentar o curso médio e superior (96\%) (Amado et al. 2009, p.305). Neste sentido, Lopes $(2004$, p. 1) fala que a tecnologia não causa mudanças apenas no que fazemos, mas também em nosso comportamento, na forma como elaboramos conhecimentos e no nosso relacionamento com o mundo.

Dentro deste contexto é possível visualizar que os jovens utilizam cada vez mais as TIC's e ferramentas de internet e de troca de mensagens via celular, e muitas vezes expõem mais do que deviam. No espaço virtual, os xingamentos e provocações atormentam as vítimas permanentemente e não ficam restritos aos momentos de convívio na escola. Wanzinack (2014) cita que "um elemento que torna a pratica de cyberbullying devastadora é a possibilidade de atingir plateias em proporções incomensuráveis, potencializando dramaticamente os sentimentos de vergonha e humilhação da vitima, a ponto de se sentirem tão indefesas que alguns casos culminam em suicídios".

Para Rocha(2012) o cyberbullying é praticado em diferentes ambientes sociais, diferentemente do bullying que se concretiza em um ambiente físico, como a escola, tornando assim uma possibilidade de falso anonimato que encoraja a agressividade.

Quando perguntado se os estudantes já haviam sido vítimas de agressão, ofensa ou intimidação pela internet, $23(9 \%)$ responderam positivamente. A forma mais comum de violência relatada foi a verbal, onde 15 estudantes relataram já terem sido vítimas de violência através de xingamentos, apelidos ou piadas; assim como o racismo, onde 4 estudantes relataram episódios pelo tipo de cabelo e cor de pele; pela situação socioeconômica, 2 estudantes revelaram brincadeiras pelo jeito "simples" de se vestir; e, 2 ocorrências pela opção religiosa. Não houve relato quanto a violência pelo gênero. 


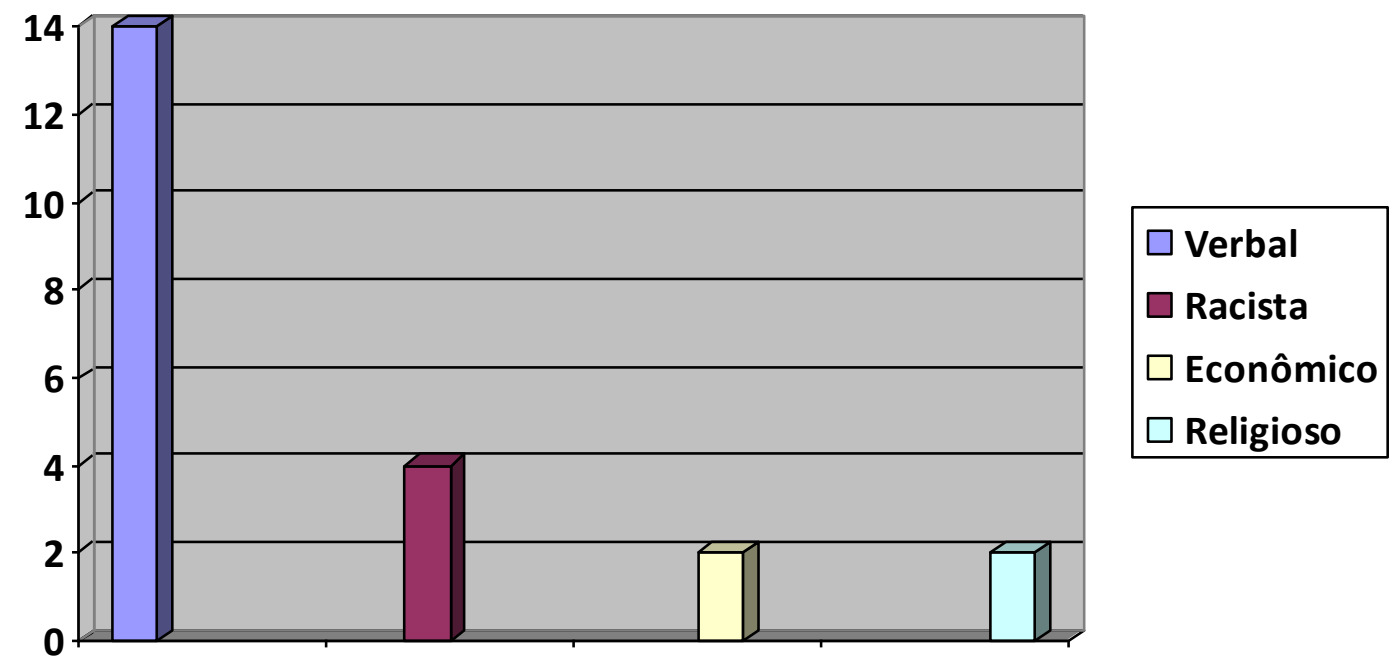

\section{Gráfico 2. Casos de Cyberbullying relatados pelos estudantes de Paranaguá/PR, composta pelas variáveis: verbal, racista, econômico e religioso. Fonte: O autor, 2014.}

Uma pesquisa, realizada em 2010, pela Organização Plan (CEATS/FIA, 2010), com mais de 5 mil estudantes brasileiros com idade compreendida entre 10 e 14 anos, apontou que $17,7 \%$ já praticaram cyberbullying, 3,5\% já praticaram e foram vítimas, enquanto $16,8 \%$ foram vítimas no mínimo uma vez ao longo de suas vidas. Dentre as vítimas, $13 \%$ foram insultados pelo celular e os $87 \%$ restantes por textos e imagens enviados por email ou sítios de relacionamento (Conte e Rossini, 2010). Outro estudo desenvolvido por Hunder (2012) analisou que pelo menos $25 \%$ dos adolescentes são vítimas de cyberbullying, corroborando com os achados desta pesquisa.

Dessa forma, Rocha (2012) explana que as interações mediadas pelo computador são virtuais mais ao mesmo tempo reais, pois as vítimas da violência virtual sofrem com esses atos, ou seja, não a uma ausência de realidade. Os agressores se escondem atrás de um aparelho cientes de que não pode ser facilmente punidos o que seria mais provável num caso frente a frente. A possibilidade de anonimato na internet é o elemento que encoraja as atitudes agressivas; inclusive quem pratica o cyberbullying, em muitos casos, sente ausência de culpa porque não está frente a frente com quem ele agride.

O acesso à internet, o uso nocivo de seus recursos e a consequente situação de vulnerabilidade que pode acometer a geração digital mobiliza discussões sobre o papel da escola na mediação, prevenção e proteção da agressão virtual. Assim educadores, por não entenderem os pedidos de ajuda ou por não saberem como agir diante do cyberbullying, necessitam programas de capacitação com o foco no uso saudável da tecnologia (Shariff, 2011).

Segundo Orpinas (2009) uma vítima de violência, como o cyberbullying, pode antecipar os "riscos" e situações que irá encontrar antes mesmo de ir para a escola. 
Dentre os sintomas psicológicos que impactam na vítima e no cotidiano escolar estão a ansiedade e depressão.

Diante disso, podemos perceber que é cada vez mais importante o controle dos pais, para que os jovens não sejam expostos a conteúdos impróprios e para que não sejam agredidos por imagens e comentários maldosos. O presente trabalho mostrou que o controle dos pais no litoral do Paraná é bem significativo, cerca de $51.5 \%$ dos alunos entrevistados diz que seus pais ou responsáveis controlam o acesso deles à internet e $48.5 \%$ disseram que seus pais ou responsáveis não tem controle.

\section{Considerações Finais}

Os resultados mostraram que os escolares do município de Paranaguá/PR estão utilizando as TIC's, sendo que o telefone celular é o dispositivo mais utilizado. Observou-se que há relatos de atos de violência através das TIC's, seguindo prevalência de âmbito nacional, como demonstrado pela literatura. Os insultos e xingamentos foram a forma mais frequente dos relatos, seguidos pelas condições socioeconômicas das vítimas.

O conhecimento e a informação adequada são elementos fundamentais para o combate, diminuição e prevenção deste fenômeno. De acordo com Orpinas (2009) 7 ações subsidiam programas de intervenção voltados à promoção de uma escola mais segura e saudável, sendo: 1. Identificação do problema; 2. Exame dos Fatores de Risco e Proteção; 3. Ações Preventivas; 4. Fortalecimento de Relações Positivas na Família; 5. Incentivo ao Desempenho Escolar; 6. Criação de Clima Escolar Positivo; e 7. Implementação de Programas de Prevenção subsidiados por dados teóricos e empíricos.

Portanto, na próxima fase do projeto será realizada a socialização dos dados teóricos e empíricos obtidos com as escolas do município de Paranaguá/PR a fim de discutir as repercussões que tais violências podem causar na educação e na vida dos estudantes, acarretando na exclusão social e educacional desses indivíduos e ações de minimização e prevenção deste fenômeno.

Para Hanewald (2010), o cyberbullying pode dar a falsa impressão de que é menos perigoso, porque não envolve violência física, porém o tormento psicológico pode levar ao suicídio de pessoas jovens. O tema se apresenta como um desafio para a gestão escolar, pois o meio virtual apresenta contornos fluidos, difíceis de supervisionar, mas que devem necessariamente envolver a escola, bem como família/responsáveis. Para a pesquisadora, as situações de cyberbullying que iniciam no computador em casa durante a noite, podem continuar no dia seguinte na escola e transformar-se em bullying face a face. Medidas tornam-se, portanto, necessárias, tais como: espaços de discussão e formação de professores/as, sensibilizando-os/as para o tema; realização de discussões e oficinas com estudantes, estimulando a eleição de monitores/as e formação de lideranças dentro da comunidade escolar, que ajudem a denunciar e combater o problema; elaboração e divulgação de material informativo (cartazes, pôsteres, kits educacionais, vídeos); disseminação de informações atualizadas (em páginas da internet, jornais e informativos escolares); estabelecimento de canais de apoio e suporte às vítimas, que podem incluir meios telefônicos (disque-denúncia, por exemplo), ou virtuais (salas de 
chat, fóruns, blogs ou comunidades em redes virtuais), para que possam trocar experiências, criando redes de apoio e solidariedade. Alternativamente, os/as estudantes podem ser estimulados/as a produzir seus próprios materiais de cybersegurança, individualmente ou em grupos, como atividades formativas. Campanhas de conscientização, tais como semanas anti-bullying ou dias dedicados a conscientizar a comunidade escolar, integração de lições de cybersegurança ao currículo escolar, performances teatrais, gincanas ou outros métodos também podem ser adotados. Em síntese, o problema não pode continuar em silêncio.

\section{Referências}

Amado, J., Matos, A., Pessoa, T. e Jäger, T. (2009) "Cyberbullying: um desafio à investigação e à formação". Revista Interacções. 13. 301-326.

Bandeira, C. M.; Hutz, C. S. (2010). "As implicações do bullying na autoestima de adolescentes". Revista Semestral da Associação Brasileira de Psicologia Escolar e Educacional. 14. 131-138.

Calbo, A. S.; Busnello, F. B.; Rigoli, M. M.; Schaeffer, R. L. F.; Kristensen, C. H. (2009). "Bullying na escola: comportamento agressivo, vitimização e conduta prósocial entre pares”. Contextos Clínicos. 2(2).73-80.

CASAGRANDE, Lindamir Salete; TORTATO, Cintia de Souza Batista; CARVALHO, Marília Gomes de. Bullying: Quando a brincadeira vira violência. In: CASAGRANDE, Lindamir Salete; LUZ, Nanci Stancki da; CARVALHO, Marília Gomes de. Igualdade na Diversidade: enfrentando o sexismo e a homofobia. $1^{\mathrm{o}}$ Edição, Curitiba, PR: Utfpr, 2011. Cap. 9, p. 209-241.

CEATS, Centro de Empreendedorismo Social e Administração em Terceiro Setor; FIA, Fundação Instituto de Administração. (2010) "Bullying escolar no Brasil: relatório final”. São Paulo.

Conte, C. P. e Rossini, A. E. S. (2010) “Aspectos jurídicos do cyberbullying”. Revista FMU Direito. São Paulo. 24(34), páginas 46-65.

Gomes, A. E. G.; Rezende, L. K. (2011) "Reflexões sobre bullying na realidade brasileira utilizando a técnica de análise de conteúdo: revisão bibliográfica". Cadernos de Pós-Graduação em Distúrbios do Desenvolvimento.11(1). 112-119.

IBGE, Instituto Brasileiro de Geografia e Estatística. (2010) "Censo Demográfico de 2010".

Disponível em: http://www.cidades.ibge.gov.br/xtras/perfil.php?lang=\&codmun=411820>. Acesso em: 05 de julho de 2014.

IPARDES, Instituto Paranaense de Desenvolvimento Econômico e Social. (2012) "Caderno Estatístico - Município de Paranaguá". Curitiba: IPARDES, dez.

Lopes, J. J. (2004) “A introdução da informática no ambiente escolar". $<$ http://www.clubedoprofessor.com.br/artigos/artigojunio.htm> 
Oliveira, E. R. C.; Ferreira, A. P.; Costa, M. R. (2011) "Nos retratos da violência escolar: bullying uma forma escolar de violência". Conexão Ciência. 6.1.

Orpinas, P. (2009) "La prevención de la violencia escolar: de la teoria a la práctica". In: Berger, C.; Lisboa, C. Violencia escolar: estúdios y possibilidades de intervención em latinoamerica. Santiago. Editorial Universitária.

Hanewald, Ria. Cyber Bullying in educational contexts: what, where and why? ACEC Digital Diversity Conference. Melbourne, Austrália, p.6-9, April, 2010.

Hunder, N. (2012) "Vencendo o cyberbullying: problemas da vida real". $1^{\circ}$ Edição. São Paulo. Hedra Educação.

Rocha, T. B. (2012) "Cyberbullying: ódio, violência virtual e profissão docente". Editora Líber Livro.

Shariff, S. (2011) “Cyberbullying: questões e soluções para a escola, sala de aula e a família" Porto Alegre: Artmed.

UFPR, Universidade Federal do Paraná. (2008) "Projeto Político-Pedagógico do Setor Litoral da UFPR". Matinhos.

UFPR, Universidade Federal do Paraná. (2009) "Projeto Político-Pedagógico do Curso de Informática e Cidadania". Matinhos.

Wanzinack, C. (2014) "Bullying e Cyberbullying: faces silenciosas da violência". In. Sierra, J. C.; Signorelli, M. C. Diversidade e educação: interseções entre corpo, gênero e sexualidade, raça e etnia. Matinhos. UFPR Litoral. 